\title{
Leveraging Language Proficiency Through Cultural Intelligence to Improve Global
} Virtual Team Performance

\author{
Robert D. Stephens ${ }^{1}$, Longzhu Dong ${ }^{2}$, and Ana Maria Soares ${ }^{3}$ \\ ${ }^{1}$ Department of Management, Marketing, and Entrepreneurship, Shippensburg University, USA \\ ${ }^{2}$ Department of Management and Marketing, University of Wisconsin-Eau Claire, USA \\ ${ }^{3}$ Department of Management, University of Minho, Portugal
}

\begin{abstract}
Author Note
Correspondence concerning this article should be addressed to Robert D. Stephens, Department of Management, Marketing, and Entrepreneurship, John L. Grove College of Business, Shippensburg University, 1871 Old Main Drive, Shippensburg, Pennsylvania 17257. Email:




\begin{abstract}
We examine the effect of group level skills on group processes and collective outcomes in multilingual, multicultural global virtual teams. We test a moderated mediation model in which cultural intelligence (CQ) is found to moderate the relationship between average team perceived English language proficiency, team creativity, and team performance with the variables of elaboration of task information and task conflict serving as mediators in the relationship. Data was gathered from 5,852 people working in 895 teams to test the model. Results show that the average English proficiency of the team is positively associated with both team creativity and overall team performance through the mediator of elaboration of task information. CQ moderates this relationship such that teams high in average CQ are much better at elaborating task information as average team English skills increase while teams with low average CQ experience only minimal increases in task elaboration as English skills increase. The model is not significant, however, when using average levels of task conflict on the team as a mediating variable. CQ does not moderate conflict, and conflict is not significantly related to either creativity or overall team performance. We explore implications for managerial practice and directions for future research.
\end{abstract}

Keywords: GVTs; CQ; English proficiency; elaboration of task-relevant information; task conflict; team creativity; team performance 


\section{Leveraging Language Proficiency Through Cultural Intelligence to Improve Global}

\section{Virtual Team Performance}

Studies of team performance often focus on individual characteristics of team members in efforts to explain team level performance. While we recognize that ultimately it is individuals who make up teams, we also believe that there are important team level characteristics that contribute to team level outcomes. The combination of skill sets within a team, as well as the average levels of those skills on the team, can contribute to processes and outcomes in ways that transcend individual characteristics viewed in isolation.

Growing globalization in business and education contexts has led to a rise in the number of multicultural/multinational teams, including Global Virtual Teams (GVTs)(Gonzalez-Perez, et al., 2014; Rowell, 2016). In fact, a recent survey by the consultancy and training firm RW3 found that $89 \%$ of the 1,620 executive survey respondents work on GVTs with over $27 \%$ participating in four or more teams (RW3 Culture Wizard, 2018).

Many studies have pointed out both the benefits and challenges of these work groups compared to traditional co-located teams. Frequently mentioned challenges include problems associated with space-time dispersion such as time zone differences, communication delays, and heavy reliance on asynchronous modes of communication (Homan et al., 2006). In multilingual GVTs, these challenges are especially relevant because team members may face additional communication difficulties due to members' lack of proficiency in a common language. Linguistic difficulties may amplify other difficulties faced by GVTs and negatively impact the formation of a shared understanding within the group, limiting the group's ability to interact and reflect as a team (Fleischmann et al., 2017). 
Much previous work on GVTs has focused on issues of diversity of team members. This is a natural line of inquiry since, by definition, these teams are global and are comprised of members from different cultural and linguistic backgrounds as well as usually having members with diverse functional backgrounds as well. Diversity along a number of dimensions within non-virtual teams has been seen to be simultaneously both a potential benefit and a challenge (Kearney et al., 2009; Stahl et al., 2010). Specifically, as Kankanhalli et al. state, "while diversity has been celebrated for stimulating creativity and allowing a variety of skills to be brought to bear on problems at hand, it may also reduce team cohesion and increase conflict" (2007: 238). However, many studies have also found evidence of the negative impact of diversity in team functioning and dynamics (Homan et al., 2007). The diversity of backgrounds inherent in GVTs includes different sources of heterogeneity in the characteristics of the members. "Since cultural diversity increases the complexity, conflict, confusion, and ambiguity of communication, it sets higher challenges for leaders and members" (Shachaf, 2008).

The examination of diversity as a major explanatory variable in GVT studies has obscured the potential importance of other factors that could shape team processes and results. Work in global virtual teams requires both unique skills and effective team processes in order to achieve desired group outcomes. While skills are attributable to individuals working within teams, the collective level of skills at the team level is an often-overlooked concept. Furthermore, processes are dependent on collective action and are best analyzed at the team level where interactions among individuals take place. There is a relative dearth of literature taking a team skills approach to examining team processes and performance. We propose a shift away from the focus on diversity as a predictor of team outcomes and toward an emphasis on mean team skill levels as an important determinant of GVT process effectiveness and outcome success. 
In particular we focus on language proficiency as a key ground level skill within GVTs which serves as a necessary but not sufficient condition for effective team performance. We also identify team level cultural intelligence as another group skill that contributes positively to more effective group processes and better team performance.

The aim of this paper is to test the impact of language proficiency as a group skill on the processes and outcomes of teamwork within global virtual teams. Despite its importance for the quality of team work and performance, language remains largely neglected in management studies (Fleischmann et al., 2017; Marlow et al., 2018). Specifically, we consider elaboration of task information and conflict as relevant variables shaping the process of collaboration within groups and identify team creativity and overall team performance on a structured task as outcome variables. Since many previous studies have also identified cultural intelligence (CQ) as having an important role in determining group performance (Erez et al., 2013; Magnusson et al., 2014; Shirish, 2019), we also include CQ in our model and examine whether CQ moderates the mediating impact of the process variables in determining group performance.

Our study contributes to the body of knowledge on global virtual teams by illuminating the impact of group level skills and processes on group level outcomes. We demonstrate how higher levels of cultural intelligence in multilingual, multicultural teams leverage higher levels of team mean language proficiency to contribute to both process and outcome improvements for the team through a moderated mediation model.

\section{Conceptual Framework}

\section{Team Skills}

Language proficiency 
One of the fundamental challenges facing people working in multinational, multicultural, and multilingual teams is communication. These challenges are even more significant for virtual teams since communication in these teams is conducted through various lower context electronic means rather than through traditional high context face-to-face interactions as would be the case in most co-located teams. The truncated contextual cues inherent to virtual communication heighten the need for competent language skills among team members. Researchers have been much more keen to recognize the importance of language use within MNEs as a topic of investigation in recent years, and recognize that language barriers can have a strong impact on the performance of multinational organizations and groups (Barner-Rasmussen \& Aarnio, 2011; Daim et al., 2012; Fleischmann et al., 2019).

English is often used as a common denominator language in MNEs, especially among employees working in virtual teams, but as Klitmøller and Lauring point out, "variations in proficiency and style of language use will often exist between group members" (2013: 400). For non-native speakers of English, confidence in language abilities can vary across different types of communication such as speaking, listening, reading and writing. Native English speakers may be overconfident with their English skills. In fact, anecdotal evidence from practitioners indicates that, in groups composed of both native and non-native English speakers, Native English speakers are often the hardest to understand and have the most difficulty in understanding (Morrison, 2016). It is also important to point out that it is often not the actual English skills of organizational participants that impact their effectiveness within their work groups, but it is their own perceived level of language competence that dictates success. In a study of French high-tech workers, Neeley (2013) found that the responses of nonnative English speakers to interactions with native English speaking co-workers differed depending on their self-perceived fluencies in 
English rather than actual fluencies as measured by objective tests. Therefore, we would expect that perceived language proficiency is a strong reflection of actual language skills and should be a key determinant of both processes and outcomes in global virtual teams that use a common language in their work.

\section{Cultural intelligence}

Cultural intelligence is defined as the ability to behave in novel ways based on the presentation of cultural differences and to be able to accurately interpret meaning in culturally diverse contexts (Earley \& Mosakowski, 2004; Earley \& Peterson, 2004). As pointed out earlier, cultural differences can cause team members to withhold information from each other across cultural fault lines or possibly misinterpret information that is shared. A low collective level of cultural intelligence in a GVT may prevent members from communicating effectively and may contribute to misunderstandings and conflict within the team (Homan et al., 2007; Meyer \& Schermuly, 2012). Conversely, the possession of cross-cultural skills could be a significant catalyst to the sharing of more information relevant to the tasks facing the team and could serve to overcome the potential misunderstandings inherent in cross-cultural contexts. In a qualitative study, Chang, Chuang and Chao (2011) find that cultural adaptation, communication quality, and trust all have positive effects on the performance of virtual teams. Similarly, Eisenberg and Mattarelli (2017) find that GVT members with high cultural intelligence may be able to play the crucial role of "multicultural broker", and can help teams to bridge across multiple cultural identities thereby enhancing both the quality and quantity of knowledge sharing which might otherwise be stifled by cultural differences.

\section{Team Processes}




\section{Elaboration of Task-Relevant Information}

The value of teamwork as compared to individual work is the ability of groups to gain synergy through collective delegation of tasks, sharing diverse perspectives and bringing unique resources to bear on the tasks at hand. As such, the elaboration of task relevant information is a fundamental component of the processes needed to obtain maximum synergies within any group work. Elaboration of task information has been defined as the exchange, discussion, and integration of ideas, knowledge, and perspectives that are relevant to a team's tasks (Van Knippenberg et al., 2004). Thus, true elaboration of information extends far beyond merely sharing information. It also includes team members' efforts to provide more detailed explanations of their ideas to fellow group members, to spend time discussing these ideas as a group, to integrate information collectively and then determine how to make application of the shared knowledge to their joint tasks (Hoever et al., 2012).

Extant research has indicated that informational diversity can improve group performance by stimulating the elaboration of task-relevant information and perspectives since each member may contribute with different perspectives and background to the tasks at hand. Higher effort dedicated to share, process and integrate information in group interaction may impact group performance positively (Homan et al., 2007). Exchanging information and ideas in order to clarify task parameters, objectives, and outputs allows teams to fully use their pool of resources and achieve better performance (Resick et al., 2014). Informational diversity may also, however, result in subgroup categorizations which can affect the group cohesion and motivation to collaborate, leading to conflict. This being the case, informational diversity can undermine rather than enhance performance (Homan et al., 2007). Homan et al (2007) also found that elaboration of task-relevant information mediated the impact of diversity beliefs in informationally diverse 
groups on performance. On the other hand, cultural differences can at times have a positive effect on knowledge sharing, as studies conducted in the context of co-located teams have shown (Dougherty et al., 1992; Earley \& Mosakowski, 2000) This is likely because interactions in intercultural groups can make the contextual and tacit knowledge more explicit through the process of sharing (Klitmøller \& Lauring, 2013).

\section{Task Conflict}

Task conflict occurs in teams when members do not share a common understanding of how the team should proceed in order to achieve collective goals and objectives (Wakefield et al., 2008). Task conflict also includes issues of what roles members on the team should adopt, the allocation of specific duties to individuals in the team, and what level of responsibility should be allocated to each member (Kankanhalli et al., 2006). Task conflict has been found to be more likely in a virtual context than among co-located teams due to the challenges posed by sharing information asynchronously and through lower-context forms of communication (Lira et al., 2008). GVTs are particular susceptible to higher levels of task conflict. In fact, in the context of cross-border virtual team collaboration, language-related fault lines may lead to power struggles and subgroup formation (Hinds et al., 2014). According to Kankanhalli, Tan and Wei (2006, p. 238) "Within GVTs, cultural diversity is likely to contribute to both task and relationship conflict while functional diversity may result in task conflict”. It has been suggested by some research, however, that conflict in virtual teams may be less severe when leaner forms of communication are used by team members to communicate (Stahl et al., 2010). This could be due to the fact that team members with lower levels of language proficiency are able to take more time in forming their communication using leaner methods, which are usually asynchronous and allow for the 
ability to use tools such as spelling and grammar checkers to filter communications (Klitmøller \& Lauring, 2016).

\section{Team Outcomes}

\section{Creativity}

Creativity has been the object of attention in several areas of research. In general, creativity refers to generating novel and useful ideas (Kurtzberg, 2010a; Yuan et al., 2018). Teams are often looked at as a means to generate creativity. Extant research has shown that there are both potential benefits and limitations to creativity in teams (Kurtzberg, 2010b). In fact, research of group level creativity emphasizes that group interactions will favor the generation of novel ideas and approaches (Kurtzberg, 2010b; Yuan et al., 2018). Having access to different resources, information sources and contributions will leverage the generation of new solutions. Hence, by definition, being able to communicate in a common language to exchange and discuss ideas, information and knowledge among team members, i.e. elaboration of task relevant information, contributes positively to creativity. Based on cognitive neuroscience, Lauring and Klitmøller (2017: 30) have argued that communicating in languages learned later in life will constrain communication and "result not only in reduced comprehension and hampered rhetorical skills but also in decreased communication frequency". Based on these ideas, Lauring and Klitmøller go on to argue for an inclusive language approach, recommending that team members try to cultivate "an attitude of being open and acceptant of variations in styles of speaking, vocabulary, and proficiency levels" (2017: 30) in order to make individuals more comfortable and willing to communicate and "also potentially diminish subgroup formation based on variations in the common language." 


\section{Team Performance}

There are many ways to define and measure performance in both co-located and virtual teams, with common dimensions usually including a discussion of the quality of tasks performed, the quantity of tasks completed, and the speed of task completion (Paul et al., 2016; Tröster et al., 2014). Performance can be measured subjectively by supervisors, peers, or outside experts or objectively evaluated based on the parameters of the tasks involved (Meyer \& Schermuly, 2012; Tavoletti et al., 2019). Performance can also be defined and measured by the team itself based on a collective elaboration of team goals and a mutual assessment of the degree of attainment of these goals (Rico et al., 2012).

In this study, we have chosen to focus on team output quality as the performance measure. This type of measure is particularly well-suited to structured tasks of limited duration, such as the task performed by the teams we study.

\section{Research Model}

Based on the discussion above, we propose the following research model and hypotheses.

Insert figure 1 about here

H1: Elaboration of task relevant information mediates the positive relationship between team English proficiency and team creativity.

$\mathrm{H}$ 2: Elaboration of task information mediates the positive relationship between team English proficiency and overall team performance. 
H3: CQ moderates the indirect effect between team English proficiency and team creativity through elaboration of task relevant information. When CQ is high, the indirect effect is stronger. H4: CQ moderates the indirect effect between team English proficiency and team performance through elaboration of task relevant information. When CQ is high, the indirect effect is stronger. H5: Conflict mediates the negative relationship between team English proficiency and team creativity.

H6: Conflict mediates the negative relationship between team English proficiency and overall team performance.

H7: CQ moderates the indirect effect between team English proficiency and team creativity through conflict. When CQ is high, the indirect effect is stronger.

H8: CQ moderates the indirect effect between team English proficiency and team performance through conflict. When CQ is high, the indirect effect is stronger.

\section{Method}

\section{Sample}

Hypotheses were tested using the data from the X-Culture Project. X-Culture Project is a large-scale international experiential learning project that involves over $5000 \mathrm{MBA}$ and bachelor's level business students from 100 universities in about 40 countries on six continents every semester. The students are placed in global virtual teams of about seven, each student coming from a different country. Working with people from around the globe and dealing with cultural differences, time-zone dispersion, and global communication challenges, the teams complete a consulting project for a multi-national company. The project involved development of a solution to real-life business challenges presented by real-life companies. The task involved 
market research, market entry plan development, and product design. The project was supervised by instructors with rich business consulting experience and managed as a regular business consulting project.

For the present study, we used sample of participants who participated in the project in 2018. The total number of participants was 5,852 people working in 895 teams, of which 2,501 people (399 teams) participated the project in the Spring semester, 3,351 people (496 teams) participated in the Fall semester. In the Spring semester, participants were asked to do evaluate each other's performance only at the end of the project. However, in the Fall semester peer review was done on a weekly basis, which provided an opportunity for us to investigate our hypotheses. Thus, a dummy variable was created as the independent variable, where "0" $=2014$ Spring (with peer review), and "1" = 2014 Fall (with peer review). All the hypotheses were tested using Multivariate Analysis of Variance (MANOVA) method in SPSS 24 package program (Mertler \& Vannaatta, 2010).

\section{Measures}

\section{GVT team performance}

Team performance was measured using report quality score which was graded by 5-6 independent experts (International Business professors and client company representatives). The reports were evaluated on a 7-point scale along the following dimensions: economic viability, creativity and novelty of the ideas, clarify of the supporting arguments, formatting and presentation. For the analysis, we used an average score across all five dimensions.

\section{Team Creativity}

Every week during the project, each GVT needs to complete a peer evaluation survey on ten dimensions on a scale from 1 (poor) to 5 (excellent), such as team member effort and team 
member work ethic etc. Team creativity was measured using an average score of peer evaluation on the dimension called "quality of the ideas and intellectual contribution" of each team member over the entire project.

\section{Team English Proficiency}

Team English proficiency was measured using the average of each team member's selfreported English skill levels on a scale from 1 (poor) to 5 (excellent). Sample questions include "How would you describe your ability to understand spoken English?", "How would you describe your ability to understand texts written in English?”, "How would you describe your ability to speak English?”, "How would you describe your ability to write in English?”.

\section{Elaboration of Task Relevant Information}

Elaboration of Task Relevant Information was measured on a using the four-item scale developed by Kearney, Gebert, and Voelpel (2009). The sample items are "The members of this team complement each other by openly sharing their knowledge"; "The members of this team carefully consider all perspectives in an effort to generate optimal solutions"; "The members of this team carefully consider the unique information provided by each individual team member"; "As a team, we generate ideas and solutions that are much better than those we could develop as individuals." Cronbach's alpha for this scale was .86.

\section{Team Task Conflict}

Team task conflict was measured using average self-reported task conflict frequency on a scale from 1 to 7. The question that participants answer is "How many conflicts, arguments, or unpleasant situations have you experienced last week over task arguments, Such as business decision, answer to challenge questions?" Data was collected on weekly basis, for the analysis, we used an average score across all eight weeks. 
Cultural Intelligence. Cultural intelligence was measured using the 20-item Cultural Intelligence Scale (Ang et al., 2007). This scale was designed to measure the four facets: metacognition, cognition, motivational, and behavior on a 7-point Likert scale. A sample item for meta-cognition is "I check the accuracy of my cultural knowledge as I interact with people from different cultures". A sample item for cognition is "I know the arts and crafts of other cultures", a sample item for motivational dimension is "I enjoy interacting with people from different cultures.", a sample item for behavioural dimension is "I use pause and silence differently to suit different cross-cultural situations." Cronbach's alpha for this scale was .86.

Controls. Age (an average score of age of all team members), gender (male percentage), team size, English skill (self-reported scale from 0 to 100), readiness test score (familiarity with the X-Culture Project) and online collaboration experience (an average score of total time in previous online collaboration projects)

\section{Results}

Correlation results, descriptive results, mean and standard deviation are shown in the Table 1 .

Insert table 1 about here

Insert table 2, figure 2 and figure 3 about here 
As shown in Table 2 and Table 3. Most of our eight hypotheses were supported by the data. Hypotheses 1 and 2 suggest the mediating role of task information elaboration on the positive relationship between English proficiency and two dependent variables--creativity and team performance. Our results fully supported these two hypotheses and both indirect effects are positive $(.10 * *[.03, .17] ; 03 * *[.01, .07])$. Hypotheses 3 and 4 suggest that cultural intelligence moderates the above indirect effects. To test such moderated mediation effects, we followed Hayes's (2012) approach and tested the index of moderated mediation. As shown in Table 2, both hypothesis 3 and 4 were supported with indexes of moderated mediation of $.23 * *$ and .08 respectively. We also plotted the interaction in Figure 2 and 3. In hypotheses 5 to 8, we proposed that task conflict plays the mediating role instead of elaboration of task information. We tested these hypotheses in a similar way. However, none of these hypotheses were supported. Part of reason may be due to the fact that all the tasks in the X-Culture project are highly structured. Every week participants received specific instructions about what the task is and how to complete the task, thus there is less room for participants to pursue or explore different perspectives, and in turn lowers the chances of task conflict to emerge and influence team outcomes.

\section{Implications and Future Research Directions}

This paper sought to investigate the impact of team skills, specifically language proficiency and cultural intelligence, in team performance (overall performance and creativity). Our study is based on team level rather than individual data thus focusing on how the combination of individual characteristics contributes a shared pool of assets that leverage team outcomes. Our results indicate that average team English proficiency is a significant skill that impacts team processes and team outcomes. When combined with higher levels of average cultural intelligence on the team, English skills are leveraged to improve the elaboration of task relevant information which in turn has a positive impact on both team creativity and overall performance. These findings indicate that management should be sensitive to both average team English proficiency and average cultural intelligence when assembling global virtual teams. 
Team members that have high levels of these skills are valuable additions to GVTs, since they raise the average level of proficiency of the team as a whole. This would indicate that effective teams could be composed of a mix of high and medium or low skill members, since it is the average skill level that predicts team performance. Another practical implication of our study is that effective management of GVTs must include training about attitudes towards cultural values and differences. Specially for complex tasks, the value of proficiency and elaboration on taskrelevant information is important to achieve better results within global virtual teams that often have a high level of both cultural and linguistic diversity.

Future research should try to take a more fine-grained approach to team skill composition. Various specific team skill configurations are possible, such as teams composed of all relatively low-skill members, teams of all high-skill members, teams of all average-skill members, and combinations of high/low, high/average, and average/low skill members. It is quite possible that outcome variables will be significantly different across these different team configurations, despite the average skill levels on the team. In other words, teams composed of all average skill level members may perform much better than teams with some outstanding members and some members that have very low English proficiency and/or cultural intelligence. Other potential avenues for explanation include situations in which teams do not communicate in English as a common language, but instead use a mix of languages or a language other than English. Under these circumstances, multilingual and highly culturally intelligent team members are likely to be able to make an even larger contribution to overall team success. 
Figure 1 Research Model

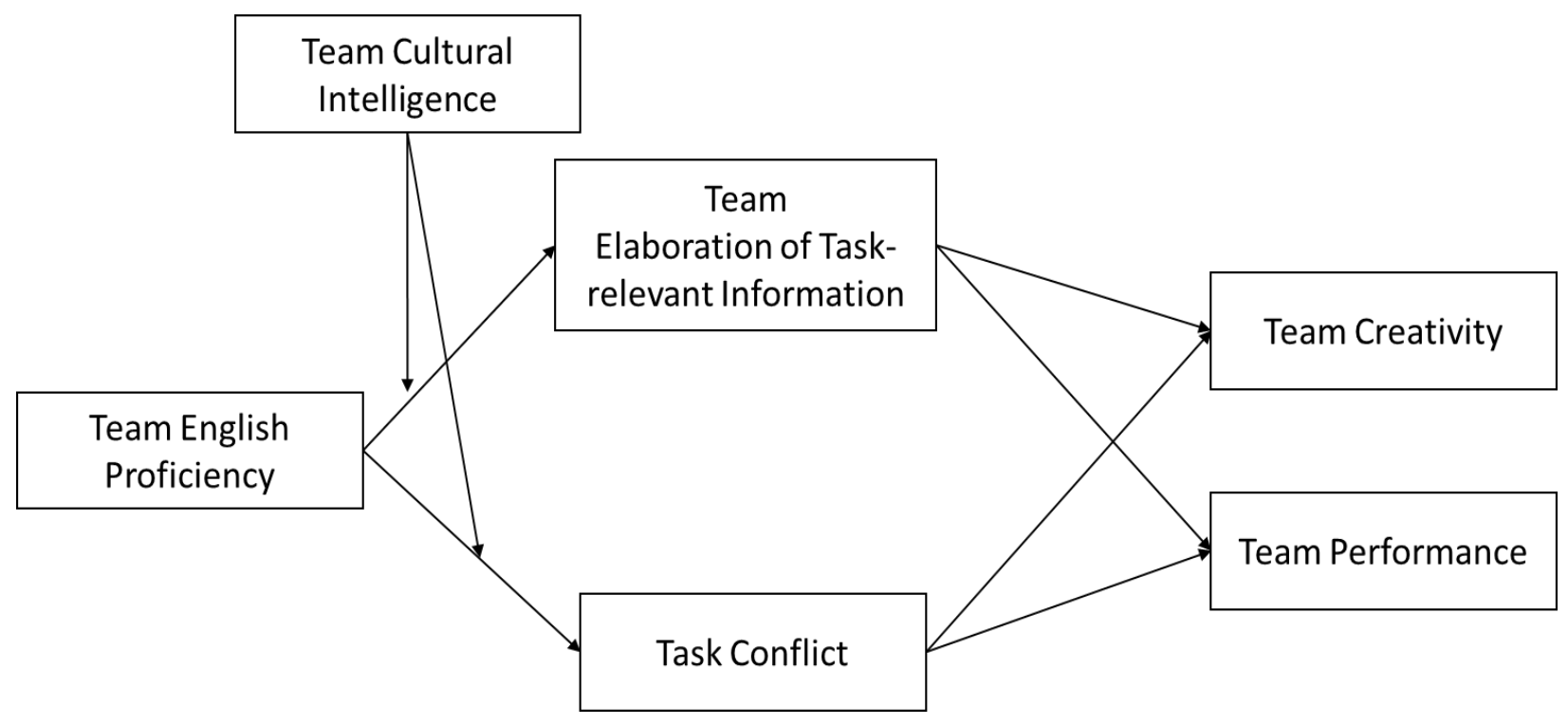




\section{Table 1 Correlation and Descriptive Analysis}

\begin{tabular}{|c|c|c|c|c|c|c|c|c|c|c|}
\hline & Mean & $\begin{array}{l}\text { Std. } \\
\text { Deviation }\end{array}$ & 1 & 2 & 3 & 4 & 5 & 6 & 7 & 8 \\
\hline 1. Team Average Age & 20.06 & 8.58 & & & & & & & & \\
\hline 2. Team Size & 5.01 & 0.89 & $-.03 *$ & & & & & & & \\
\hline 3. Team Male Percentage & 5.18 & 1.34 & $.38 * *$ & 0.00 & & & & & & \\
\hline 4. Team Performance & 6.11 & 18.23 & $-.69 * *$ & $.06 * *$ & $-.27 * *$ & & & & & \\
\hline 5. Team Creativity & 8.65 & 1.77 & $.94 * *$ & $-.04 * *$ & $.39 * *$ & $-.69 * *$ & & & & \\
\hline 6. Team English proficiency & 4.76 & 2.04 & $.27 * *$ & $-.19 * *$ & $.60 * *$ & $.04 *$ & $.28 * *$ & & & \\
\hline 7. Team Task Conflict & 4.23 & 0.70 & $.26 * *$ & 0.01 & $.32 * *$ & $-.20 * *$ & $.24 * *$ & $.70 * *$ & & \\
\hline 8. Team Cultural intelligence & 4.20 & 0.56 & 0.03 & $.14 * *$ & 0.00 & $.07 *$ & $.09 * *$ & $-.47 * *$ & $.19 * *$ & \\
\hline 9. Team Elaboration on Task Relevant Information & 3.76 & 0.63 & $-.10 * *$ & $.12 * *$ & $.05 * *$ & $.10 * *$ & $-.08 * *$ & $-.22 * *$ & -0.02 & $.55 * *$ \\
\hline
\end{tabular}


Table 2 Moderated Mediation Results - Team Elaboration on Task Relevant Information as mediator

\begin{tabular}{|c|c|c|c|c|c|c|}
\hline \multirow[t]{2}{*}{ Predictors } & \multicolumn{2}{|c|}{$\begin{array}{l}\text { Mediator } \\
=\text { TETI }\end{array}$} & \multicolumn{2}{|c|}{$\begin{array}{c}\text { DV } \\
=\text { Team Creativity }\end{array}$} & \multicolumn{2}{|c|}{$\begin{array}{c}\text { DV } \\
=\text { Team Performance }\end{array}$} \\
\hline & $\bar{B}$ & $S E$ & $\bar{B}$ & $S E$ & $\bar{B}$ & $S E$ \\
\hline Intercept & $3.95 * *$ & .14 & $2.22 * *$ & .16 & $4.69 * *$ & .14 \\
\hline Team Size & .04 & .03 & $-.18 * *$ & .03 & -.10 & .06 \\
\hline Team Male Percentage & .00 & .00 & .00 & .00 & .00 & .00 \\
\hline Team English Proficiency (TEP) & $.14^{* *}$ & .06 & .02 & .05 & $.37 * *$ & .06 \\
\hline Team Cultural Intelligence (TCI) & $.33 * *$ & .05 & ------- & ------- & ------- & ------- \\
\hline TEP*TCI & $.40 * *$ & .16 & ------ & ------- & ------- & ------ \\
\hline $\begin{array}{l}\text { Team Elaboration on Task Information } \\
\text { (TETI) }\end{array}$ & ------- & ------- & $.59 * *$ & .03 & $.21 * *$ & .05 \\
\hline \multicolumn{3}{|c|}{ Direct, indirect, and total effects } & Effect & C.I.95\% & Effect & C.I.95\% \\
\hline Direct effect of TEP & & & .02 & {$[-.08 \quad .12]$} & .37 & {$[.18, .55]$} \\
\hline Indirect effect of TEP & & & .10 & {$[.03, .17]$} & .03 & {$[.01, .07]$} \\
\hline \multicolumn{7}{|l|}{ Conditional indirect effect of TEP } \\
\hline Low TCI (-1 SD) & & & -.01 & {$[-.08, .10]$} & .00 & {$[-.03, .03]$} \\
\hline High TCI (+1 SD) & & & .15 & {$[.05, .25]$} & .05 & {$[.01, .10]$} \\
\hline Test of moderated med & & & Index & BootCI $_{95 \%}$ & Index & BootCI $_{95 \%}$ \\
\hline Index of moderated mediation & & & .23 & {$[.03, .44]$} & .08 & {$[.01, .18]$} \\
\hline
\end{tabular}


Table 3 Moderated Mediation Results - Team Task Conflict as mediator

\begin{tabular}{|c|c|c|c|c|c|c|}
\hline \multirow[t]{2}{*}{ Predictors } & \multicolumn{2}{|c|}{$\begin{array}{c}\text { Mediator } \\
=\text { Team Task Conflict }\end{array}$} & \multicolumn{2}{|c|}{$\begin{array}{c}\text { DV } \\
=\text { Team Creativity }\end{array}$} & \multicolumn{2}{|c|}{$\begin{array}{c}\text { DV } \\
=\text { Team Performance }\end{array}$} \\
\hline & $B$ & $S E$ & $B$ & $S E$ & $B$ & $S E$ \\
\hline Intercept & $1.63 * *$ & .70 & $5.09 * *$ & .24 & $4.99 * *$ & .43 \\
\hline Team Size & $.09 * *$ & .16 & $-.18 * *$ & .06 & .10 & .10 \\
\hline Team Male Percentage & -.02 & .06 & -.04 & .02 & -.02 & .03 \\
\hline Team English Proficiency (TEP) & $-.15^{* *}$ & .04 & .02 & .10 & $.37 * *$ & .17 \\
\hline Team Cultural Intelligence (TCI) & $-.11 * *$ & .05 & ------- & ------- & ------- & ------- \\
\hline TEP*TCI & -.11 & .14 & ------- & ------- & ------ & ------- \\
\hline Team Task Conflict & ------- & ------- & -.16 & .02 & -.03 & .04 \\
\hline \multicolumn{3}{|c|}{ Direct, indirect, and total effects } & Effect & C.I. $95 \%$ & Effect & C.I. $95 \%$ \\
\hline Direct effect of TEP & & & .02 & {$[-.17, .22]$} & $.37 *$ & {$[.03, .71]$} \\
\hline Indirect effect of TEP & & & .05 & {$[-.03 . .09]$} & .01 & {$[-.01, .03]$} \\
\hline \multicolumn{7}{|l|}{ Conditional indirect effect of TEP } \\
\hline Low TCI (-1 SD) & & & -.01 & {$[-.15, .11]$} & .00 & {$[-.04, .05]$} \\
\hline High TCI (+1 SD) & & & .11 & {$[-.02, .24]$} & .02 & {$[-.04, .13]$} \\
\hline \multicolumn{3}{|c|}{ Test of moderated mediation } & Index & BootCI $_{95 \%}$ & Index & BootCI $_{95 \%}$ \\
\hline Index of moderated mediation & & & .21 & {$[-.05, .50]$} & .04 & {$[-.09, .21]$} \\
\hline
\end{tabular}


Figure 2 Interaction Plot (DV= Team Creativity)

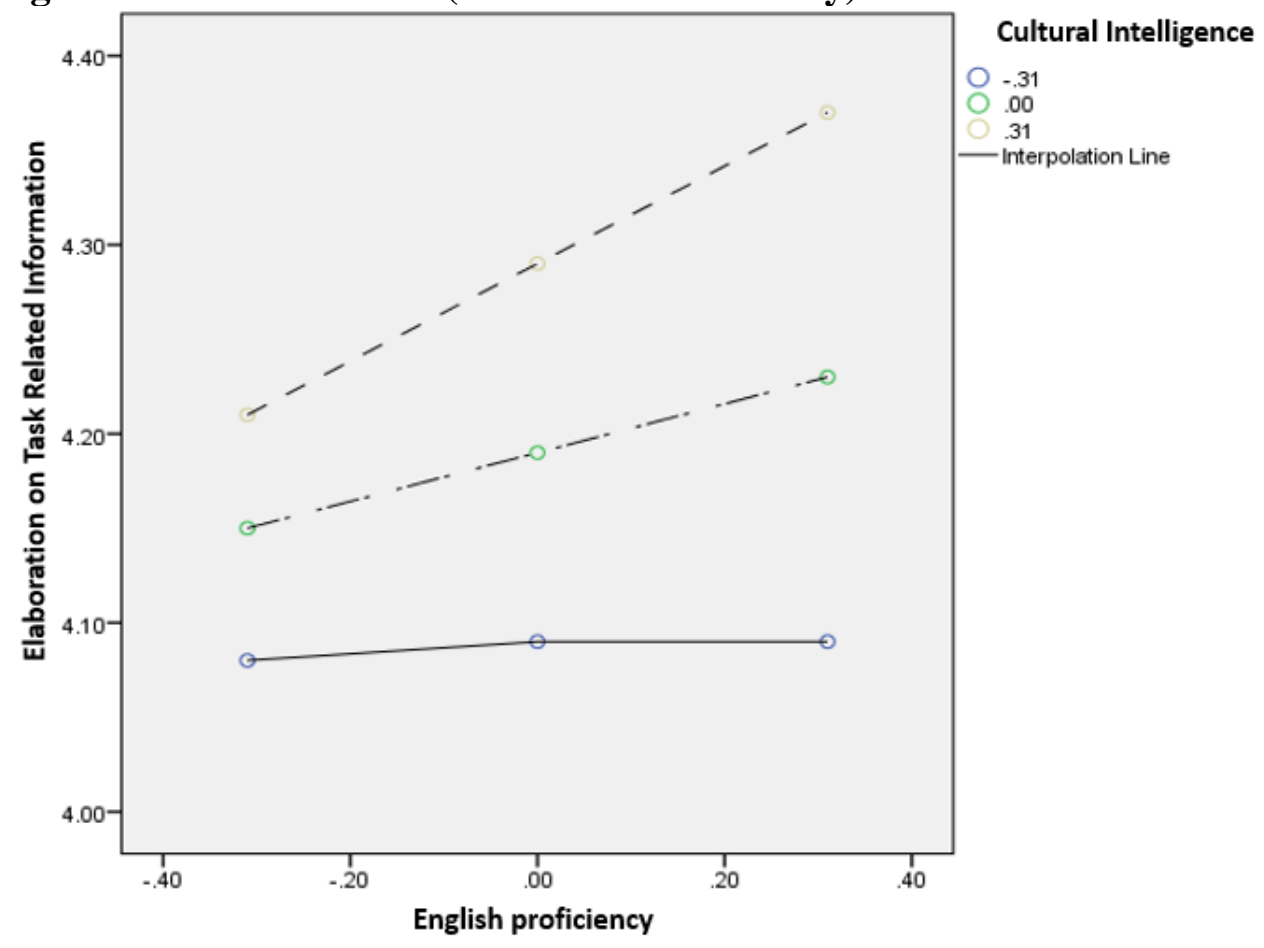

Figure 3 Interaction Plot (DV= Team Performance)

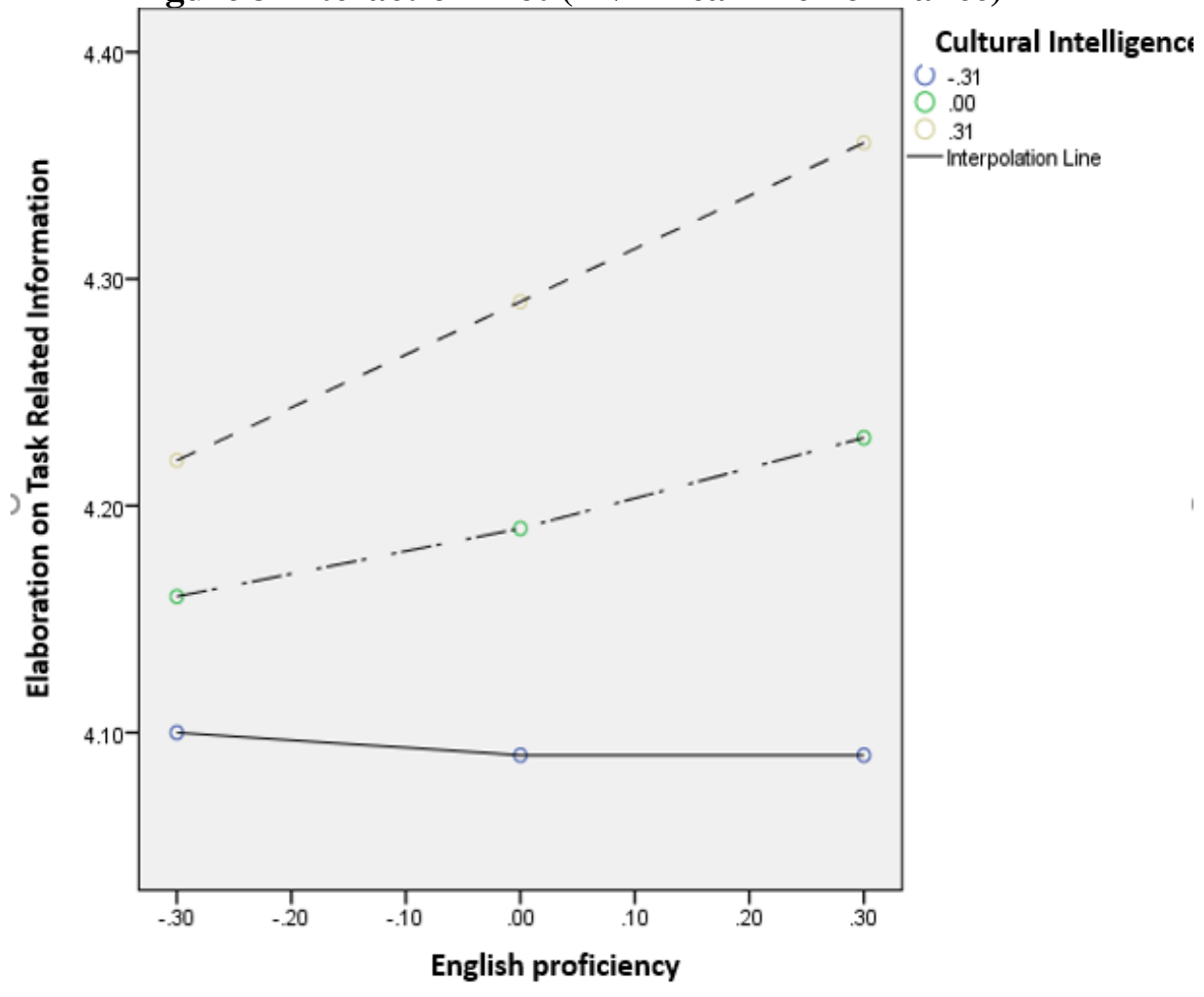




\section{References}

Barner-Rasmussen, W., \& Aarnio, C. (2011). Shifting the faultlines of language: A quantitative functional-level exploration of language use in MNC subsidiaries. Journal of World Business, 46(3), 288-295. https://doi.org/10.1016/j.jwb.2010.07.006

Chang, H. H., Chuang, S. S., \& Chao, S. H. (2011). Determinants of cultural adaptation, communication quality, and trust in virtual teams' performance. Total Quality Management and Business Excellence, 22(3), 305-329. https://doi.org/10.1080/14783363.2010.532319

Daim, T. U., Ha, A., Reutiman, S., Hughes, B., Pathak, U., Bynum, W., \& Bhatla, A. (2012). Exploring the communication breakdown in global virtual teams. International Journal of Project Management, 30(2), 199-212. https://doi.org/10.1016/j.ijproman.2011.06.004

Dougherty, K. C., Eisenhart, M., \& Webley, P. (1992). The Role of Social Representations and National Identities in the Development of Territorial Knowledge : A Study of Political Socialization in Argentina and England Published by : American Educational Research Association Stable URL: http://www.jstor.org. American Educational Research Journal, 29(4), 809-835.

Earley, P. C., \& Mosakowski, E. (2000). Creating hybrid team cultures: An empirical test of transnational team functioning. Academy of Management Journal, 43(1), 26-49. https://doi.org/10.2307/1556384

Earley, P. C., \& Mosakowski, E. (2004). Cultural Intelligence. Harvard Buisness Review, (October), 139149.

Earley, P. C., \& Peterson, R. S. (2004). The Elusive Cultural Chameleon: Cultural Intelligence as a New Approach to Intercultural Training for the Global Manager. Academy of Management Learning AndEducation, 3(1), 100-115.

Eisenberg, J., \& Mattarelli, E. (2017). Building Bridges in Global Virtual Teams: The Role of Multicultural Brokers in Overcoming the Negative Effects of Identity Threats on Knowledge Sharing Across Subgroups. Journal of International Management, 23(4), 399-411.

https://doi.org/10.1016/j.intman.2016.11.007

Erez, M., Lisak, A., Harush, R., Glikson, E., Nouri, R., \& Shokef, E. (2013). Going global: Developing 
management students'cultural intelligence and global identity in culturally diverse virtual teams. Academy of Management Learning and Education, 12(3), 330-355. https://doi.org/10.5465/amle.2012.0200

Fleischmann, C., Aritz, J., \& Cardon, P. (2019). Fit of language proficiency and media in global virtual teams: Which media lead to team member satisfaction and inclusion across levels of language proficiency? Academy of International Business Annual Meeting, Copenhagen.

Fleischmann, Carolin, Folter, L.-C., \& Aritz, J. (2017). The Impact of Perceived Foreign Language Proficiency on Hybrid Team Culture. International Journal of Business Communication, 232948841771044. https://doi.org/10.1177/2329488417710440

Gonzalez-Perez, M. A., Velez-Calle, A., Cathro, V., Caprar, D. V., \& Taras, V. (2014). Virtual Teams and International Business Teaching and Learning: The Case of the Global Enterprise Experience (GEE). Journal of Teaching in International Business, 25(3), 200-213. https://doi.org/10.1080/08975930.2014.925738

Hinds, P. J., Neeley, T. B., \& Cramton, C. D. (2014). Language as a lightning rod: Power contests, emotion regulation, and subgroup dynamics in global teams. Journal of International Business Studies, 45(5), 536-561. https://doi.org/10.1057/jibs.2013.62

Hoever, I. J., van Knippenberg, D., van Ginkel, W. P., \& Barkema, H. G. (2012). Fostering team creativity: Perspective Taking as Key to Unlocking Diversity's Potential. Journal of Applied Psychology, 97(5), 982-996. https://doi.org/10.1037/a0029159

Homan, A. C., van Knippenberg, D., Van Kleef, G. A., \& De Dreu, C. K. W. (2007). Bridging Faultlines by Valuing Diversity: Diversity Beliefs, Information Elaboration, and Performance in Diverse Work Groups. Journal of Applied Psychology, 92(5), 1189-1199. https://doi.org/10.1037/00219010.92.5.1189

Kankanhalli, A., Tan, B. C. Y., \& Kwok-Kee, W. E. I. (2006). Conflict and performance in global virtual teams. Journal of Management Information Systems, 23(3), 237-273. https://doi.org/10.2753/MIS0742-1222230309 
Kearney, E., Gebert, D., \& Voelpel, S. (2009). When and how diversity benefits teams: The importance of team members' need for cognition. Academy of Management Journal, 52(3), 581-598. https://doi.org/10.5465/AMJ.2009.41331431

Klitmøller, A., \& Lauring, J. (2013). When global virtual teams share knowledge: Media richness, cultural difference and language commonality. Journal of World Business, 48(3), 398-406. https://doi.org/10.1016/j.jwb.2012.07.023

Klitmøller, A., \& Lauring, J. (2016). When distance is good: A construal level perspective on perceptions of inclusive international language use. International Business Review, Vol. 25, pp. 276-285. https://doi.org/10.1016/j.ibusrev.2015.05.006

Kurtzberg, T. R. (2010a). Feeling Creative, Being Creative : An Empirical Study of Diversity and Creativity in Teams Feeling. Creativity Research Journal, 17(April 2011), 51-65. https://doi.org/10.1207/s15326934crj1701

Kurtzberg, T. R. (2010b). Feeling Creative, Being Creative : An Empirical Study of Diversity and Creativity in Teams Feeling Creative, Being Creative : An Empirical Study of Diversity and Creativity in Teams. Creativity Research Journal, 17(April 2011), 51-65. https://doi.org/10.1207/s15326934crj1701

Lauring, J., \& Klitmøller, A. (2017). Inclusive language use in multicultural business organizations: The effect on creativity and performance. International Journal of Business Communication, 54(3), 306324. https://doi.org/10.1177/2329488415572779

Lira, E. M., Ripoll, P., Peiró, J. M., \& Orengo, V. (2008). How do different types of intragroup conflict affect group potency in virtual compared with face-to-face teams? A longitudinal study. Behaviour and Information Technology, 27(2), 107-114. https://doi.org/10.1080/01449290600875151

Magnusson, P., Schuster, A., \& Taras, V. (2014). A Process-Based Explanation of the Psychic Distance Paradox: Evidence from Global Virtual Teams. Management International Review, 54(3), 283-306. https://doi.org/10.1007/s11575-014-0208-5

Marlow, S. L., Lacerenza, C. N., Paoletti, J., Burke, C. S., \& Salas, E. (2018). Does team communication 
represent a one-size-fits-all approach?: A meta-analysis of team communication and performance. Organizational Behavior and Human Decision Processes, 144(September 2017), 145-170. https://doi.org/10.1016/j.obhdp.2017.08.001

Meyer, B., \& Schermuly, C. C. (2012). When beliefs are not enough: Examining the interaction of diversity faultlines, task motivation, and diversity beliefs on team performance. European Journal of Work and Organizational Psychology, 21(3), 456-487. https://doi.org/10.1080/1359432X.2011.560383

Morrison, L. (2016). Native English speakers are the world's worst communicators. Retrieved November 20, 2019, from BBC Worklife website: https://www.bbc.com/worklife/article/20161028-nativeenglish-speakers-are-the-worlds-worst-communicators

Neeley, T. B. (2013). Language matters: Status loss and achieved status distinctions in global organizations. Organization Science, 24(2), 476-497. https://doi.org/10.1287/orsc.1120.0739

Paul, R., Drake, J. R., \& Liang, H. (2016). Global Virtual Team Performance: The Effect of Coordination Effectiveness, Trust, and Team Cohesion. IEEE Transactions on Professional Communication, 59(3), 186-202. https://doi.org/10.1109/TPC.2016.2583319

Resick, C. J., Murase, T., Randall, K. R., \& DeChurch, L. A. (2014). Information elaboration and team performance: Examining the psychological origins and environmental contingencies. Organizational Behavior and Human Decision Processes, 124(2), 165-176. https://doi.org/10.1016/j.obhdp.2014.03.005

Rico, R., Sánchez-Manzanares, M., Antino, M., \& Lau, D. (2012). Bridging team faultlines by combining task role assignment and goal structure strategies. Journal of Applied Psychology, 97(2), 407-420. https://doi.org/10.1037/a0025231

Rowell, D. (2016). GVTs — Necessary Evil or Strategic Tool ? Chief Learning Officer, (October), 14. RW3 Culture Wizard. (2018). 2018 Trends in High-Performing Global Virtual Teams.

Shachaf, P. (2008). Cultural diversity and information and communication technology impacts on global virtual teams: An exploratory study. Information and Management. 
https://doi.org/10.1016/j.im.2007.12.003

Shirish, A. (2019). Substantive Theory of Cultural Intelligence for Virtual Team Performance: A Mixed Methods Approach. Academy of Management Annual Meeting Proceedings, 2019(1), 1. Retrieved from http://10.0.21.89/AMBPP.2019.17468abstract

Stahl, G. K., Maznevski, M. L., Voigt, A., \& Jonsen, K. (2010). Unraveling the effects of cultural diversity in teams: A meta-analysis of research on multicultural work groups. Journal of International Business Studies, 41(4), 690-709. https://doi.org/10.1057/jibs.2009.85

Tavoletti, E., Stephens, R. D., \& Dong, L. (2019). The impact of peer evaluation on team effort, productivity, motivation and performance in global virtual teams. Team Performance Management, 25(5-6). https://doi.org/10.1108/TPM-03-2019-0025

Tröster, C., Mehra, A., \& van Knippenberg, D. (2014). Structuring for team success: The interactive effects of network structure and cultural diversity on team potency and performance. Organizational Behavior and Human Decision Processes, 124(2), 245-255.

https://doi.org/10.1016/j.obhdp.2014.04.003

Van Knippenberg, D., De Dreu, C. K. W., \& Homan, A. C. (2004). Work group diversity and group performance: An integrative model and research agenda. Journal of Applied Psychology, 89(6), 1008-1022. https://doi.org/10.1037/0021-9010.89.6.1008

Wakefield, R. L., Leidner, D. E., \& Garrison, G. (2008). A model of conflict, leadership, and performance in virtual teams. Information Systems Research, 19(4), 434-455. https://doi.org/10.1287/isre.1070.0149

Yuan, L., Ning, L., Jingzhou, G., Jingyu, L., \& Harris, T. B. (2018). A network view of advice-giving and individual creativity in teams: A brokerage-driven, socially perpetuated phenomenon. Academy of Management Journal, 61(6), 2210-2229. https://doi.org/10.5465/amj.2016.0212 